ASTHMA

\title{
Nebulised salbutamol administered during sputum induction improves bronchoprotection in patients with asthma
}

\author{
M Delvaux, M Henket, L Lau, P Kange, P Bartsch, R Djukanovic, R Louis
}

Thorax 2004;59:111-115. doi: 10.1136/thorax.2003.011130

See end of article for authors' affiliations

Correspondence to: Dr R Lovis, Department of Pneumology, CHU SartTilman, 4000 Liege, Belgium;

R.Louis@chu.ulg.ac.be

Received 4 June 2003

Accepted 27 October 2003
Background: Inhalation of hypertonic or even isotonic saline during sputum induction may cause bronchospasm in susceptible patients with asthma, despite premedication with $400 \mu \mathrm{g}$ inhaled salbutamol delivered by pressurised metered dose inhaler (pMDI). The bronchoprotection afforded by additional inhaled salbutamol administered through the ultrasonic nebuliser during sputum induction was investigated.

Methods: Twenty patients with moderate to severe asthma underwent sputum induction by inhaling saline $4.5 \%$ (or $0.9 \%$ if post-bronchodilation forced expiratory volume in 1 second ( $\mathrm{FEV}_{1}$ ) $<65 \%$ predicted) for 10 minutes according to two protocols given 1 week apart in random order. At visit $A$ the patients received $400 \mu \mathrm{g}$ salbutamol administered through a pMDI + spacer 20 minutes before induction while at visit $B$ the premedication was supplemented by $1500 \mu \mathrm{g}$ nebulised salbutamol inhaled throughout the induction procedure. Both the investigator and the patients were blind to the nebulised solution used. $\mathrm{FEV}_{1}$ was recorded during sputum induction at 1, 3, 5, and 10 minutes. Sputum cell counts and histamine, tryptase and albumin levels in the supernatants were determined.

Results: The mean (SE) maximal reduction in $\mathrm{FEV}_{1}$ over the 10 minute period of sputum induction was $11.7(2.8) \%$ at visit $A$, which was significantly greater than at visit $B(2.6(1.2) \%$; mean difference $9 \% 195 \%$ $\mathrm{Cl} 2.7$ to 15.4), $\mathrm{p}<0.01$ ). Total and differential sputum cell counts as well as albumin, tryptase, and histamine levels did not differ between the two visits.

Conclusion: The addition of inhaled salbutamol through an ultrasonic nebuliser markedly improves bronchoprotection against saline induced bronchoconstriction in patients with moderate to severe asthma undergoing sputum induction without affecting cell counts and inflammatory markers.
$\mathrm{S}$ ince the first description of sputum induction by Pin et al in $1992,{ }^{1}$ the technique has been widely used in asthma research. Although several studies have reported on the methodology of sputum induction, ${ }^{2}$ some outstanding issues with respect to the safety of the procedure remain. Inhalation of hypertonic saline carries the risk of severe bronchoconstriction in patients with bronchial hyperresponsiveness, ${ }^{3}$ and hypertonic saline challenge is a recognised indirect challenge to assess bronchial hyperresponsiveness in asthma. ${ }^{4}$ This has led to the recommendation of using inhaled salbutamol 200$400 \mu \mathrm{g}$ before sputum induction in patients with asthma unless measurement of bronchial responsiveness to saline is an outcome of the study. ${ }^{5}$ In most studies inhaled salbutamol has been delivered by pressurised metered dose inhaler (pMDI), some authors combining the pMDI with a spacer to improve lung deposition. Despite this type of premedication, some asthmatic patients still experience breakthrough bronchoconstriction. One way to reduce the risk of bronchoconstriction is to induce sputum by inhalation of isotonic rather than hypertonic saline, as advocated by Pizzichini et al for severe asthmatic exacerbations. ${ }^{6}$ However, even isotonic saline may be sufficiently irritating to the airways to trigger bronchospasm in asthmatic patients with very reactive airways. The dose of salbutamol and the optimal way to deliver it remains an issue for the safety of sputum induction. $^{5}$

We hypothesised that delivering salbutamol via ultrasonic nebuliser together with isotonic or hypertonic saline may provide better bronchoprotection than inhaled salbutamol pMDI $400 \mu \mathrm{g}$ alone administered through a Volumatic chamber. We have assessed 20 patients with moderate to severe asthma and compared the falls in forced expiratory volume in 1 second $\left(\mathrm{FEV}_{1}\right)$ that occurred during sputum induction when subjects were premedicated with either salbutamol pMDI $(400 \mu \mathrm{g})$ or salbutamol pMDI $(400 \mu \mathrm{g})+$ nebulised salbutamol delivered throughout the induction procedure. To ensure that nebulised salbutamol does not affect the key indicators in the sputum we compared the two induction procedures with respect to sputum cell counts and several biochemical markers-albumin as an indicator of plasma exudation and tryptase and histamine as markers of mast cell activation-two activities that may theoretically be influenced by $\beta_{2}$ agonists. ${ }^{7}$

\section{METHODS \\ Subjects}

Twenty patients with moderate to severe asthma diagnosed according to ATS criteria ${ }^{8}$ were recruited from outpatient clinics. Three had been admitted to hospital and five others had received a course of systemic corticosteroids for a severe asthma exacerbation during the previous year. The demographic and functional characteristics of the subjects are shown in table 1.

Sixteen subjects received regular treatment with inhaled corticosteroids, 11 of whom were also receiving inhaled long acting $\beta_{2}$ agonists. Two subjects were also on oral corticosteroids with a daily dose of 16 and $32 \mathrm{mg}$ methylprednisolone, respectively. Maintenance treatment was kept constant over the 4 weeks preceding the study (table 2 ). The protocol was approved by the local ethical committee and volunteers gave their written informed consent.

\section{Study design}

This was a randomised crossover study. There was a run in period during which subjects recorded their daily consumption of relief bronchodilators into diary cards. Subjects were 
Table 1 Demographic and functional characteristics of study subjects

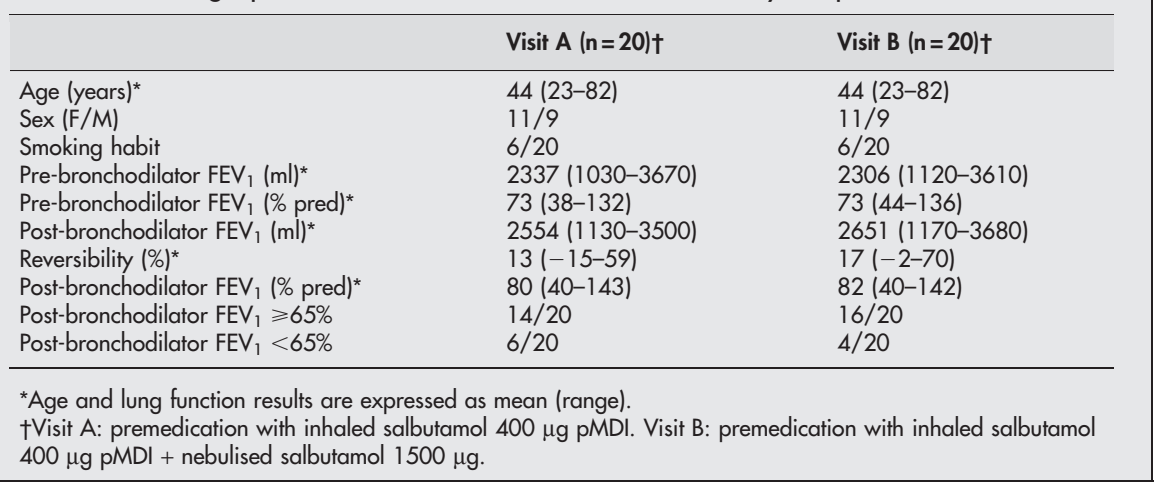

randomised to receive either inhaled salbutamol $400 \mu \mathrm{g}$ administered through pMDI and Volumatic (Glaxo Smith Kline, UK) 20 minutes before sputum induction (visit A) or the same regimen + additional nebulised salbutamol 1571 $\mu \mathrm{g}$ during the sputum induction procedure (visit B). Both the asthmatic subjects and the laboratory function technician who performed sputum induction and spirometric tests were blind to the inhaled solution used. The two sputum inductions were separated by a period of 1 week and were performed at the same time of the day $( \pm 2$ hours). There was no change in the maintenance treatment between inductions and subjects were allowed to take their usual maintenance drugs (including long acting $\beta_{2}$ agonists) on the morning of the induction. Importantly, the mean consumption of short acting bronchodilator during the preceding week and the baseline lung function values before sputum induction were similar between visits A and B (table 2).

$\mathrm{FEV}_{1}$ was measured as the best of three flow-volume curves using an electronic spirometer (Spirobank, MIR, Rome, Italy) before and 15 minutes after $400 \mu \mathrm{g}$ inhaled salbutamol, the latter value being considered as the baseline value.

Sputum induction was started with either hypertonic or isotonic saline according to post-bronchodilator $\mathrm{FEV}_{1}$. Patients with an $\mathrm{FEV}_{1} \geqslant 65 \%$ predicted inhaled $4.5 \%$ saline while those with $\mathrm{FEV}_{1}<65 \%$ predicted were given $0.9 \%$ saline instead. Two patients had a post- bronchodilator $\mathrm{FEV}_{1}$ slightly less than $65 \%$ predicted at visit A $(62 \%$ and $64 \%$ predicted, respectively) but more than $65 \%$ at visit B $(66 \%$ and $67 \%$ predicted, respectively). As visit A was the first visit for these two patients, they also inhaled isotonic saline at their second visit (visit B) for consistency.

\section{Sputum induction}

Saline was inhaled through an ultrasonic nebuliser (Devilbiss 2000), the mean output of which was calculated to be $0.93 \mathrm{ml} / \mathrm{min}$. The cup of the nebuliser was filled with $50 \mathrm{ml}$

Table 2 Treatment characteristics of study subjects

\begin{tabular}{lll}
\hline & Visit A $(\mathbf{n}=\mathbf{2 0})^{*}$ & Visit B $(\mathbf{n = 2 0})^{*}$ \\
\hline $\begin{array}{l}\text { Short acting } \beta_{2} \text { agonists } \\
\text { (puffs/week) }\end{array}$ & $16(0-70)$ & $14(0-64)$ \\
$\begin{array}{l}\text { Treated with long acting } \\
\beta_{2} \text { agonists }(\mathrm{n})\end{array}$ & 11 & 11 \\
$\begin{array}{l}\text { Treated with inhaled } \\
\text { corticosteroids (n) }\end{array}$ & 16 & 16 \\
$\begin{array}{l}\text { Treated with theophylline (n) } \\
\text { Treated with oral }\end{array}$ & 1 & 1 \\
$\begin{array}{l}\text { corticosteroids (n) } \\
\text { No controller medication (n) }\end{array}$ & 2 & 2 \\
\hline
\end{tabular}

*Visit A: premedication with inhaled salbutamol $400 \mu \mathrm{g}$ pMDI; visit B: premedication with inhaled salbutamol $400 \mu \mathrm{g} \mathrm{pMDI}+$ nebulised salbutamol $1500 \mu \mathrm{g}$ hypertonic/isotonic saline to which was added $1.75 \mathrm{ml}$ salbutamol solution at $5 \mathrm{mg} / \mathrm{ml}$. The dose of nebulised salbutamol was dependent on the duration of sputum induction and was calculated by multiplying the concentration of salbutamol in the cup of the nebuliser $(169 \mu \mathrm{g} / \mathrm{ml})$ by the output of the nebuliser $(0.93 \mathrm{ml} / \mathrm{min})$ and the duration of the induction. $\mathrm{FEV}_{1}$ was measured at $1,3,5$, and 10 minutes after starting inhalation. Inhalation of saline was stopped after 10 minutes or when a fall in $\mathrm{FEV}_{1}$ of $>20 \%$ from baseline had occurred. After performing spirometric measurements at 5 and 10 minutes the subjects were asked to rinse their mouth with tap water and to cough up sputum into a plastic container. For safety reasons, $\mathrm{FEV}_{1}$ was measured 10 and 20 minutes after the end of the induction in every patient. Two subjects who still had a fall in $\mathrm{FEV}_{1}$ of $>20 \%$ at this time received additional nebulised salbutamol and ipratropium bromide and were kept under observation until their $\mathrm{FEV}_{1}$ value had returned to within $5 \%$ of baseline.

\section{Sputum processing}

Samples were poured into a $50 \mathrm{ml}$ polypropylene tube, weighed, and diluted with a threefold weight of a phosphate buffered saline (PBS) solution for homogenisation. The samples were then rocked at room temperature for $20 \mathrm{~min}$ utes and centrifuged at $400 \mathrm{~g}$ for 10 minutes at $4^{\circ} \mathrm{C}$. The supernatant was stored at $-80^{\circ} \mathrm{C}$ until biochemical analyses for albumin and histamine. The cellular phase was dispersed in $1 \mathrm{ml}$ PBS without $\mathrm{Ca}^{2+}$ and $\mathrm{Mg}^{2+}$ solution for total cell counts using a manual haemocytometer. The differential cell count was performed on cytospins stained with Diff-Quick by counting 500 cells under a light microscope.

\section{Biochemical assays}

Albumin was measured by rocket electrophoresis as previously described. ${ }^{\circ}$ Histamine was measured by RIA (Immunotech, Marseille, France) with a sensitivity of $0.02 \mathrm{ng} / \mathrm{ml}$. Tryptase was measured by an immunoassay (UniCAP, Pharmacia, Uppsala, Sweden) with a sensitivity of $\mathrm{l} \mathrm{ng} / \mathrm{ml}$.

\section{Statistical analyses}

Changes in $\mathrm{FEV}_{1}$ during sputum induction were expressed as mean (SE), and sputum cell counts and biochemical markers as median (range). Assessment of the significance of a bronchoconstriction during the sputum induction for each procedure was performed using a one sample Student's $t$ test. Comparisons of the maximal falls in $\mathrm{FEV}_{1}$ between the two procedures were performed by a paired Student's $t$ test. Comparisons of sputum cell counts and biochemical markers between the two procedures were performed by the Wilcoxon rank sum test, whereas reproducibility was assessed by calculating the intraclass coefficient of correlation as previously 


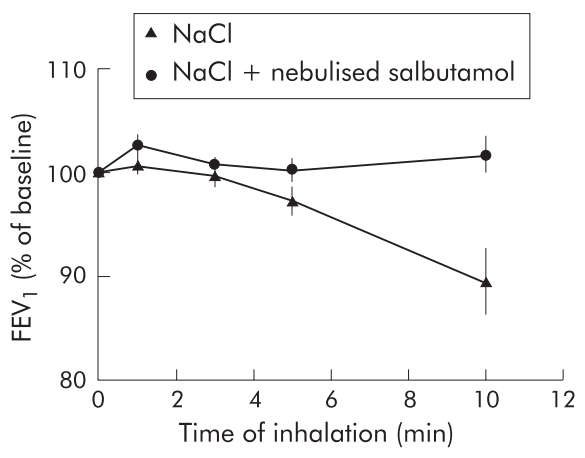

Figure 1 Time course of bronchoconstriction during sputum induction by inhalation of hypertonic or isotonic saline in 20 patients with moderate to severe asthma. Results expressed as mean (SE) values.

described. ${ }^{10} \mathrm{p}$ values of $<0.05$ were considered statistically significant. Given the repeatability of the functional and biochemical parameters and setting a risk error $\alpha$ at 0.05 , our sample size had a power of $98 \%, 96 \%, 82 \%$, and $84 \%$ to detect a $50 \%$ inhibition in the fall in $\mathrm{FEV}_{1}$ and of the sputum levels of albumin, histamine and tryptase, respectively.

\section{RESULTS}

There was no significant difference between post-bronchodilator $\mathrm{FEV}_{1}$ values measured before starting sputum induction on visits A and B (table 1). All the subjects inhaled saline for 10 minutes on both occasions. Sputum induction caused significant bronchospasm that peaked at 10 minutes and reached $10.4(3.2) \%(p<0.01)$ when subjects were premedicated with $400 \mu \mathrm{g}$ salbutamol inhaled through a pMDI and spacer (visit A). In contrast, inhalation of the same amount of saline did not produce any significant fall in $\mathrm{FEV}_{1}$ when the patients received nebulised salbutamol in addition to conventional premedication (visit $\mathrm{B}$, fig 1 ). The maximal fall in $\mathrm{FEV}_{1}$ over the 10 minute period was $11.7(2.8) \%$ at visit $\mathrm{A}$ and $2.6(1.2) \%$ at visit $B$ (fig 2 ). The mean (95\% CI) difference for the maximal fall in $\mathrm{FEV}_{1}$ between visits $\mathrm{A}$ and B was $9 \%$ (2.7 to 15.4), p<0.01. Six of the 20 patients had a fall in $\mathrm{FEV}_{1}$ of $>20 \%$ at 10 minutes when premedicated with the conventional procedure while none reached this threshold when receiving nebulised salbutamol.

At visit A the mean maximal fall in $\mathrm{FEV}_{1}$ was 11.1 (3.6)\% $(\mathrm{p}<0.05$, one sample $t$ test) in patients who inhaled hypertonic saline and $13.2(4.9) \%(\mathrm{p}<0.05)$ in patients who

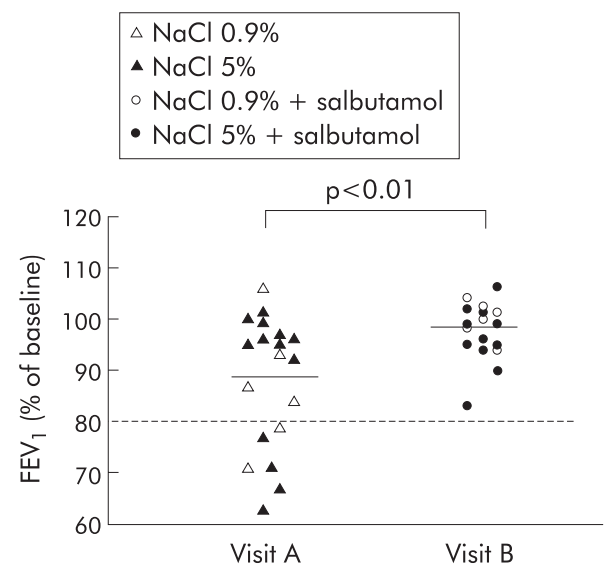

Figure 2 Distribution of the maximal falls in forced expiratory volume in 1 second $\left(\mathrm{FEV}_{1}\right)$ at visit $\mathrm{A}(\mathrm{NaCl})$ and visit $\mathrm{B}(\mathrm{NaCl}+$ nebulised salbutamol).

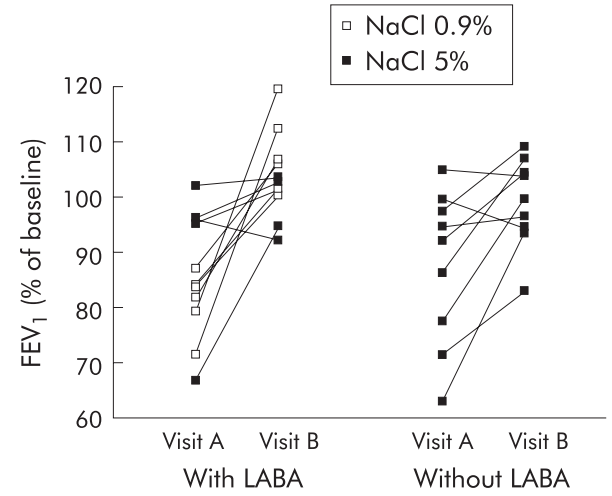

Figure 3 Comparison of the maximal falls in $\mathrm{FEV}_{1}$ between patients treated and not treated with long acting $\beta_{2}$ agonists (LABA).

inhaled isotonic saline (post-bronchodilator $\mathrm{FEV}_{1}<65 \%$ predicted). The magnitude of the falls in $\mathrm{FEV}_{1}$ with the conventional procedure was inversely related to baseline FEV $_{1}(r=-0.46, p<0.05)$ and directly related to both the extent of bronchodilation after inhaled salbutamol $400 \mu \mathrm{g}$ $(r=0.58, \mathrm{p}<0.01)$ and the consumption of $\beta_{2}$ agonist in the preceding week $(r=0.44, \mathrm{p}=0.05)$.

At visit $A$, patients who were regularly treated with long acting $\beta_{2}$ agonists $(n=11)$ had a fall in $\mathrm{FEV}_{1}$ of $11.2(3.8) \%$ compared with $12.5(4.5) \%$ in those not treated with long acting $\beta_{2}$ agonists $(n=9)$. When receiving nebulised salbutamol, the fall in $\mathrm{FEV}_{1}$ was $2.4(1.7) \%$ in patients on regular treatment with long acting $\beta_{2}$ agonists and only $3(1.6) \%$ in patients not so treated (fig 3 ).

Mean (SE) $\mathrm{FEV}_{1}$ values measured 10 and 20 minutes after the end of sputum induction at visit A were 7.1 (1.9)\% and $4.3(2.4) \%$, respectively. Two subjects still had a fall in $\mathrm{FEV}_{1}$ of more than $20 \%$ by this time which was quickly reversed to less than $5 \%$ of baseline by nebulised salbutamol $(2500 \mu \mathrm{g})$ and ipratropium bromide $(250 \mu \mathrm{g})$. At visit B there was no late bronchoconstriction following sputum induction since mean $\mathrm{FEV}_{1}$ values remained above $95 \%$ of baseline at 10 and 20 minutes.

Although 18 patients produced an adequate sputum sample on at least one occasion, only 15 produced readable samples on both occasions allowing for comparison between the two procedures. Sputum induction failed in two patients at visit $\mathrm{A}$ and in two others at visit $\mathrm{B}$. One patient was unable to produce any sample at any visit. In the patients who produced two adequate samples there was no significant difference between sputum cell counts and sputum albumin, tryptase and histamine levels measured at either visit (table 3).

\section{DISCUSSION}

This study shows that the addition of salbutamol $1500 \mu \mathrm{g}$ in the ultrasonic nebuliser during sputum induction reinforces the bronchoprotection obtained with $400 \mu \mathrm{g}$ inhaled salbutamol through pMDI in patients with moderate to severe asthma. Improved bronchoprotection is observed irrespective of current treatment with long acting $\beta_{2}$ agonists. In addition, inhalation of a high dose of salbutamol does not modify cellular and mediator activity in the airway inflammatory process as evidenced by sputum cell counts, and albumin, tryptase and histamine levels.

Our data confirm that inhaling hypertonic and even isotonic saline carries the risk of significant bronchospasm in moderate to severe asthmatics despite premedication with salbutamol $400 \mu \mathrm{g}$ delivered by pMDI, which highlights the need to improve the safety of the procedure. We have shown 
Table 3 Sputum cell counts and biochemical markers

\begin{tabular}{lllll}
\hline & Visit A & Visit B & p value & ICCC \\
\hline Squamous cells (\%) & $5(1-46)$ & $6(0-52)$ & $>0.05$ & 0.04 \\
Non-squamous cells $\left(\times 10^{6} / \mathrm{g}\right)$ & $1.8(0.3-37.8)$ & $1.5(0.3-15.5)$ & $>0.05$ & 0.41 \\
Viability (\%) & $68(46-94)$ & $72(36-84)$ & $>0.05$ & 0.53 \\
Macrophages (\%) & $35(1-74)$ & $23(2-92)$ & $>0.05$ & 0.61 \\
Lymphocytes (\%) & $0.4(0-2.4)$ & $1(0.2-2.6)$ & $>0.05$ & 0.10 \\
Neutrophils (\%) & $47(13-99)$ & $55(1-97)$ & $>0.05$ & 0.82 \\
Eosinophils (\%) & $1(0-35)$ & $2(0-48)$ & $>0.05$ & 0.74 \\
Epithelial cells (\%) & $4(0-27)$ & $3(0-15)$ & $>0.05$ & 0.52 \\
Albumin ( $\mu \mathrm{g} / \mathrm{l})$ & $152(43-380)$ & $133(54-231)$ & $>0.05$ & 0.29 \\
Tryptase & $1.29(0.31-7.32)$ & $1.36(0.34-3.66)$ & $>0.05$ & 0.65 \\
Histamine (ng/ml) & $3.5(1.1-66)$ & $4.9(0.8-61)$ & $>0.05$ & 0.77 \\
\hline Results are expressed as median (range). & & & \\
p values indicates the value of the Wilcoxon rank sum test between visits A and B. & & \\
ICCC=intraclass coefficient of correlation. & & & \\
\hline
\end{tabular}

that complementary salbutamol $(1500 \mu \mathrm{g})$ inhaled through an ultrasonic nebuliser markedly reduces the intensity of bronchospasm seen in patients with moderate to severe asthma undergoing sputum induction. None of the 20 patients studied had a fall in $\mathrm{FEV}_{1}$ of more than $20 \%$ during sputum induction when receiving nebulised salbutamol compared with six patients who had a fall in $\mathrm{FEV}_{1}$ of more than $20 \%$ (range $20.3-37.2 \%$ ) at the end of sputum induction when only receiving $400 \mu \mathrm{g}$ inhaled salbutamol through pMDI. In our study the rate of significant bronchospasm $(30 \%)$ with standard premedication is slightly higher than that reported by Fahy et al (14\%) in a recent multicentre study of asthmatics whose baseline $\mathrm{FEV}_{1}$ values were very similar to those of our subjects. ${ }^{11}$

In agreement with previous studies, ${ }^{12}{ }^{13}$ we found that both baseline $\mathrm{FEV}_{1}$ values and $\beta_{2}$ agonist consumption are parameters that may influence the magnitude of bronchospasm following inhalation of saline. It is therefore worth noting that these two parameters were similar between visits $\mathrm{A}$ and $\mathrm{B}$, making comparison between the two study days valid. The relationship between the dose of inhaled salbutamol and the extent of bronchoprotection has only been studied over a narrow range of concentrations so far. Bel and colleagues $^{14}$ showed that salbutamol 200 and $400 \mu$ g inhaled through a pMDI were both very efficient in shifting to the right the concentration of histamine or methacholine provoking a fall in $\mathrm{FEV}_{1}$ of $20 \%$ or more $\left(\mathrm{PC}_{20}\right)$ with a small dose related effect for $\mathrm{PC}_{20}$ histamine but not for $\mathrm{PC}_{20}$ methacholine. ${ }^{14}$ Inhalation of salbutamol $100-400 \mu \mathrm{g}$ by MDI produces strong bronchoprotection against methacholine that is, however, weakly proportional to the dose since $80 \%$ of protection is already achieved with $100 \mu \mathrm{g} .{ }^{15}$ On the other hand, inhalation of $1600 \mu \mathrm{g}$ salbutamol dry powder on top of regular treatment with salmeterol (50 $\mathrm{g}$ twice daily) or formoterol ( $12 \mu \mathrm{g}$ twice daily) did not increase the bronchoprotection towards methacholine. The inability of a dose of salbutamol similar to the one we used and administered through a dry powder inhaler to further improve the bronchoprotection given by long acting $\beta_{2}$ agonists ${ }^{16}$ therefore suggests that, in our study, the ultrasonic nebulisation itself may well reinforce the bronchoprotection obtained with salbutamol.

By showing no difference in the magnitude of bronchospasm induced by saline inhalation between patients with and without long acting $\beta_{2}$ agonists, our results indicate that it would be unwise to consider that asthmatic patients are always protected against saline induced bronchoconstriction when regularly treated with long acting $\beta_{2}$ agonists. The tolerance in bronchoprotection produced by chronic usage of $\beta_{2}$ agonists may be involved. ${ }^{17}$ However, it should be kept in mind that the patients in our study who received long acting $\beta_{2}$ agonists also suffered from more severe asthma, exhibiting the poorest baseline lung function, and were therefore the most likely to show a dramatic change in $\mathrm{FEV}_{1}$ after saline.

It is interesting that the delivery of high dose salbutamol into the airways does not alter the profile of sputum cells nor its albumin, tryptase and histamine content. Inhalation of hypertonic saline may trigger mast cell degranulation ${ }^{18}$ and favour vascular leakage ${ }^{19}$ into the airways. On the other hand, there is evidence in the literature that $\beta_{2}$ agonists can prevent mast cell degranulation and inhibit plasma exudation. ${ }^{7}$ As these two properties may theoretically partly contribute to the bronchoprotective effect of $\beta_{2}$ agonists, ${ }^{20}$ we wished to determine whether inhalation of a high dose of salbutamol, compared with a low dose, has any effect on the sputum content of mast cell derived mediators and a marker of plasma exudation. Our results show that high dose salbutamol had no effect on the levels of histamine, tryptase, or albumin. This suggests that the greater bronchoprotective effect of high dose salbutamol is neither related to mast cell stabilisation nor to the anti-exudative effect during sputum induction.

This study shows that additional inhalation of salbutamol through an ultrasonic nebuliser improves the safety of sputum induction in patients with moderate to severe asthma without altering its cellular and biochemical content. We believe that this may be of practical importance to the investigation of airways inflammation in patients with moderate to severe asthma.

\section{Authors' affiliations}

M Delvaux, M Henket, L Lau, P Kange, P Bartsch, R Djukanovic, R Louis, Department of Pneumology, CHU Sart-Tilman, Liege, Belgium, and Respiratory Cell and Molecular Biology, University of Southampton, UK

\section{REFERENCES}

1 Pin I, Gibson PG, Kolendowicz R, et al. Use of induced sputum cell counts to investigate airway inflammation in asthma. Thorax 1992;47:25-9.

2 Diukanovic R, Sterk PJ, Fahy JV, et al. Standardised methodology of sputum induction and processing. Eur Respir J Suppl 2002;37:1s-2s.

3 Schoeffel RE, Anderson SD, Altounyan RE. Bronchial hyperreactivity in response to inhalation of ultrasonically nebulised solutions of distilled water and saline. BMJ (Clin Res Ed) 1981;283:1285-7.

4 Joos GF, O'Connor B, Anderson SD, et al. Indirect airway challenges. Eur Respir J 2003;21:1050-68.

5 Pizzichini E, Pizzichini MM, Leigh R, et al. Safety of sputum induction. Eur Respir J Suppl 2002;37:9s-18s.

6 Pizzichini MM, Pizzichini E, Clelland L, et al. Sputum in severe exacerbations of asthma: kinetics of inflammatory indices after prednisone treatment. Am J Respir Crit Care Med 1997;155:1501-8.

7 Barnes PJ. Beta-adrenergic receptors and their regulation. Am J Respir Crit Care Med 1995;152:838-60.

8 American Thoracic Society. Standards for the diagnosis and care of patients with chronic obstructive pulmonary disease (COPD) and asthma. Am Rev Respir Dis 1987; 136:225-44. 
9 Rajakulasingam K, Polosa R, Lau LC, et al. Comparative nasal effects of bradykinin and histamine: influence on nasal airways resistance and plasma protein exudation. Thorax 1993;48:324-9.

10 Louis R, Shute J, Goldring K, et al. The effect of processing on inflammatory markers in induced sputum. Eur Respir J 1999;13:660-7.

11 Fahy JV, Boushey HA, Lazarus SC, et al. Safety and reproducibility of sputum induction in asthmatic subjects in a multicenter study. Am J Respir Crit Care Med 2001; 163:1470-5.

12 ten Brinke A, de Lange $\mathrm{C}$, Zwinderman $\mathrm{AH}$, et al. Sputum induction in severe asthma by a standardized protocol: predictors of excessive bronchoconstriction. Am J Respir Crit Care Med 2001;164:749-53.

13 Wong HH, Fahy JV. Safety of one method of sputum induction in asthmatic subjects. Am J Respir Crit Care Med 1997;156:299-303.

14 Bel EH, Zwinderman AH, Timmers MC et al. The protective effect of a beta 2 agonist against excessive airway narrowing in response to bronchoconstrictor stimuli in asthma and chronic obstructive lung disease. Thorax 1991;46:9-14.
15 Parameswaran KN Inman MD, Ekholm BP, et al. Protection against methacholine bronchoconstriction to assess relative potency of inhaled beta2agonist. Am J Respir Crit Care Med 1999;160:354-7.

16 Lipworth BJ, Aziz I. A high dose of albuterol does not overcome bronchoprotective subsensitivity in asthmatic subjects receiving regular salmeterol or formoterol. J Allergy Clin Immunol 1999;103:88-92.

17 Cockcroft DW, Swystun VA. Functional antagonism: tolerance produced by inhaled beta-2 agonists. Thorax 1996;51:1051-6.

18 Finnerty JP, Wilmot C, Holgate ST. Inhibition of hypertonic saline-induced bronchoconstriction by terfenadine and flurbiprofen. Evidence for the predominant role of histamine. Am Rev Respir Dis 1989;140:593-7.

19 Umeno E, McDonald DM, Nadel JA. Hypertonic saline increases vascular permeability in the rat trachea by producing neurogenic inflammation. J Clin Invest 1990;85:1905-8.

20 Kips JC, Pauwels RA. Long-acting inhaled beta(2)-agonist therapy in asthma. Am J Respir Crit Care Med 2001;164:923-32.

\section{LUNG ALERT}

\section{Higher tuberculosis mortality in India seen in those who have ever smoked}

$\Delta$ Gajalakshmi V, Peto R, Santhanakrishna T, Jha P. Smoking and mortality from tuberculosis and other diseases in India: retrospective study of 43000 adult male deaths and 35000 controls. Lancet 2003;362:507-15.

$\mathrm{T}$ his case-control study examined the smoking habits and medical causes of mortality in men from southern India. The death rates of current or former smokers were double

those of never smokers ( $\mathrm{RR}=2.1$ (95\% CI 2.0 to 2.2$)$ ). Of this excess mortality among smokers, a third involved respiratory disease. Tuberculosis was the chief cause of respiratory mortality (4.5 (95\% CI 4.0 to 5.0 ), smoking attributed fraction $61 \%$ ). A separate survey of 250000 men living in the urban study area found that smokers are three times more likely than never smokers to report a history of tuberculosis, corresponding to a higher rate of progression of chronic subclinical infection to clinical disease. The authors conclude that smoking, which is a cause of half the deaths from tuberculosis in men in India, increases the incidence of clinical tuberculosis.

This and similar studies will no doubt stimulate research into the mechanisms behind reactivation of tuberculosis by smoking. Some clues may be derived from the reported effects of smoking on other diseases. Smokers have a reduced incidence of sarcoidosis and extrinsic allergic alveolitis, diseases in which tumour necrosis factor- $\alpha$ (TNF- $\alpha$ ) plays a key role. Moreover, the use of anti-TNF- $\alpha$ agents for conditions such as rheumatoid arthritis leads to reactivation of tuberculosis. Collectively, these data converge on the hypothesis that smoking might oppose the release or function of TNF- $\alpha$ in the lungs. Recent work on the effects of nicotine has revealed likely pathways (Wang H, et al. Nature 2003;421:384-8; Borovikova LV, et al. Nature 2000;405:458-62).

K Dheda, G Rook

University College London and Royal Free Medical School, London, UK; kdheda@hotmail.com 